\title{
PENGARUH TIME DEMANDS OF WORK TERHADAP KEPUASAN KERJA, STRESS KERJA, DAN TURNOVER INTENTION KARYAWAN \\ (Studi Pada Karyawan PT. Bank Tabungan Negara (Persero) Tbk. Cabang Harapan Indah, Bekasi)
}

\author{
Anisah Uswatun Hasanah*, Suharnomo ${ }^{1}$ \\ Anisahuswatun@yahoo.co.id \\ Jurusan ManajemenFakultas Ekonomika dan Bisnis Universitas Diponegoro \\ Jl. Prof. Soedharto SH Tembalang, Semarang 50239, Phone: +622476486851
}

\begin{abstract}
The aim of this research is to analyze the impact time demands of work, on job satisfaction, job stress, and employee turnover intention PT. Bank Tabungan Negara (Persero) Tbk. Cabang Harapan Indah, Bekasi

This study is using path analysis with SmartPLS 2.0.M3. The population that used in the study is all the employees of PT. Bank Tabungan Negara (Persero) Tbk. Cabang Harapan Indah, Bekasi, which are 108 respondents. The amount of the sample is determined by the census method of the entire employee. However the sample that has been applied into 85 respondents significantly decreased into 85people.

The results have shown that the time demands of work do not significantly influence turnover intention. Furthermore the time demands of work have no significant effect on job satisfaction. Employee satisfaction negatively affect on turnover intention. Job satisfaction is not successfully mediating the relationship between the time demands of work and turnover intention. Time demands of work have positive influence on job stress. Job stress has positive effect on turnover intention. Job stress has been successfully mediating the relationship between the time demands of work and turnover intention. Job stress negatively affect with job satisfaction. Job satisfaction also has been successfully mediating the relationship between job stress and turnover intention.
\end{abstract}

Keywords : Time Demands of Work, Job Satisfaction, Job Stress, Turnover Intention

\section{PENDAHULUAN}

Penelitian ini menyoroti mengenai halhal yang berkaitan dengan tuntutan waktu kerja yang tinggi serta kaitannya dengan kepuasan kerja, stress, serta keinginan karyawan untuk keluar dari organisasi. Jam kerja merupakan hal yang berkaitan erat antara karyawan dengan perusahaan dan pekerjaan mereka. Lamanya waktu kerja karyawan biasanya telah disepakati saat awal melakukan kontrak kerja dengan perusahaan.

Waktu kerja normal yang berlaku di Indonesia sekitar 8 jam per harinya dengan total 40 jam per minggu, namun di luar itu seringkali perusahaan menuntut karyawan mereka untuk bekerja lebih lama dari jam kerja normal yang telah ditentukan dikarenakan adanya pekerjaan yang harus diselesaikan atau alasan lain yang mengharuskan karyawan tetap tinggal di kantor walau jam kerja telah selesai atau pada saat akhir pekan. Selain itu karyawan yang membawa pekerjaan mereka saat jam kantor selesai dan melanjutkannya di rumah dikarenakan alasan-alasan tertentu juga dapat digolongkan sebagai tingginya tuntutan waktu kerja. Berdasarkan penelitian terdahulu yang dilakukan oleh Wickramasinghe (2010) time demands of work memiliki pengaruh negatif dan 
signifikan terhadap kepuasan kerja karyawan, hal ini memiliki makna bahwa semakin tinggi tuntutan waktu kerja yang dirasakan karyawan maka akan semakin rendah tingkat kepuasan mereka terhadap pekerjaannya. Menurut Robbins (2008) kepuasan kerja merupakan sikap yang ditunjukkan oleh seseorang terhadap pekerjaannya, ini menunjukkan kepuasan mereka terhadap persepsi apa yang akan mereka terima dibanding dengan apa yang mereka dapatkan sebenarnya.

Menurut Kanwar (2012) kepuasan kerja dan komitmen organisasional memiliki hubungan penting terhadap turnover intention karyawan di dalam organisasi. Turnover intention mengacu kepada keputusan karyawan untuk keluar atau tetap bertahan di dalam suatu organisasi (Huning dan Thomson, 2010). Karyawan yang merasa puas akan pekerjaannya cenderung ingin menetap di perusahaan tersebut dan tidak berniat untuk mencari pekerjaan lainnya. Selain itu turnover intention dapat juga dipengaruhi secara langsung oleh time demands of work. Berdasarkan penelitian terdahulu oleh Wickramasinghe (2010) dijelaskan bahwa time demands of work berpengaruh positif dan signifikan terhadap turnover intention karyawan, hal ini menjelaskan bahwa semakin tinggi tuntutan waktu kerja yang dirasakan karyawan maka akan meningkatkan keinginan karyawan untuk mengundurkan diri dari perusahaan tempatnya bekerja. Tingkat turnover intention yang rendah disuatu perusahaan akan membawa dampak baik terhadap perusahaan karena dapat menghemat biaya perekrutan karyawan baru untuk menggantikan karyawan yang keluar, dan biaya investasi yang telah dikeluarkan dalam melatih dan mengembangkan karyawan tidak terbuang dengan percuma.

Menurut teori yang telah berkembang time demands of work dapat juga mempengaruhi tingkat stress kerja pada karyawan. Hal ini dibuktikan oleh penelitian terlebih dahulu yang dilakukan oleh Nadem dkk. (2013), hasil penelitian menunjukkan bahwa stress kerja dipengaruhi oleh berbagai faktor diantaranya kelebihan beban kerja, kelebihan waktu kerja, kelebihan kinerja, ambiguitas peran dan work family conflict. Stress kerja merupakan suatu kondisi ketegangan yang mempengaruhi emosi, proses berpikir dan kondisi seseorang (Handoko, 2001).

Stress yang dialami karyawan dengan tingkat yang tinggi dapat membawa pengaruh negatif terhadap perusahaan, dimana karyawan dengan tingkat stress yang tinggi tidak dapat maksimal dalam melakukan pekerjaannya yang akan membawa dampak buruk terhadap kinerjanya serta mempengaruhi kinerja perusahaan itu sendiri. Selain itu Menurut Handoko (2001) stress dianggap menjadi suatu penyebab dari timbulnya bebagai macam gangguan fisik pada karyawan, seseorang yang mengalami stress daya tahan tubuhnya akan melemah sehingga dapat mengganggu karyawan dalam bekerja. Stress juga dapat membuat seseorang tidak dapat berkonsentrasi, mudah marah, dan sulit dalam menghadapi lingkungan.

Penelitian ini dilakukan berdasarkan fenomena gap mengenai time demands of work pada PT. Bank Tabungan Negara (Persero) Tbk. Cabang Harapan Indah, Bekasi. Berdasarkan wawancara diketahui bahwa perusahaan memberlakukan jam kerja lembur bagi karyawan apabila ada tugas yang belum selesai dikerjakan atau ada pekerjaan yang menuntut karyawan untuk menyelesaikannya pada hari itu juga. Jam kerja lembur terhitung setelah jam kerja normal berakhir, yakni setelah pukul 16.30 sampai dengan selesai yang kemudian upah lembur ini akan dibayarkan dan diterima karyawan pada bulan berikutnya. Untuk waktu lembur itu sendiri biasanya terjadi sekitar dua sampai dengan tiga kali dalam seminggu dan akan selesai paling maksimal hingga malam hari. Pada hari Sabtu dan Minggu perusahaan terkadang tetap memperkerjakan para pegawainya apabila dibutuhkan. Fenomena akhir bulan menuntut seluruh karyawan untuk bekerja lebih lama dari jam kerja normal karena perusahaan membebankan pekerjaan yang lebih berat pada saat tersebut. Selain itu pada saat akhir tahun seluruh karyawan juga diarahkan untuk lembur dan bekerja lebih lama karena pada saat itu banyak pekerjaan yang harus diselesaikan oleh karyawan, mengingat akhir tahun ialah waktu dimana perusahaan melakukan laporan-laporan tahunan dan lainlain. Jam istirahat kantor yang berlaku ialah satu jam setiap harinya, terhitung mulai pukul 12.00 sampai dengan 13.00. Namun pada karyawan bidang tertentu jam istirahat 
mereka terhitung lebih sedikit, yakni teller, customer service, dan karyawan lain yang berhubungan langsung dengan nasabah. Hal ini dikarenakan perusahaan tetap memberikan pelayanan kepada nasabah pada jam istirahat kantor sehingga pada saat tersebut karyawan yang akan beristirahat harus bergantian dengan karyawan lainnya.

\section{TINJAUAN PUSTAKA}

\section{Teori Time Demands of Work}

Time demands of work mengacu pada tingginya waktu yag digunakan karyawan dalam menyelesaikan pekerjaannya. Menurut Wickramasinghe (2010) tuntutan waktu kerja (time demands of work) dapat dijabarkan dalam tiga indikator, yakni bekerja pada waktu yang panjang bahkan sampai dengan malam hari, pergi bekerja pada akhir pekan, dan membawa pekerjaan kantor ke rumah apabila tugas belum diselesaikan pada hari tersebut.

\section{Teori Kepuasan Kerja}

Menurut Robbins dan Judge (2008) kepuasan kerja merupakan sikap yang ditunjukkan oleh seseorang terhadap pekerjaannya, ini menunjukkan kepuasan mereka terhadap persepsi apa yang akan mereka terima dibanding dengan apa yang mereka dapatkan sebenarnya. Menurut Handoko (2001) kepuasan kerja adalah keadaan emosional karyawan mengenai pekerjaan mereka, perasaan menyenangkan ataupun tidak menyenangkan yang dirasakan dalam bekerja. Kreitner dan Kinicki (2001) mengatakan bahwa ada lima faktor yang dapat menciptakan kepuasan kerja. Faktorfaktor tersebut ialah sebagai berikut;

1. Need Fufillment (Pemenuhan Kebutuhan), kepuasan kerja seseorang ditentukan berdasarkan sejauh mana pekerjaan yang mereka jalani dapat memenuhi kebutuhan mereka.

2. Discrepancies (Perbedaan), kepuasan kerja seseorang ditentukan dengan seberapa besar perbedaan perbandingan antara harapan seseorang dengan kenyataan yang mereka peroleh.

3. Value Attainment (Pencapaian Nilai), kepuasan merupakan hasil dari persepsi seseorang atas suatu pekerjaan yang memenuhi nilai kerja yang dianggap penting bagi pekerja.

4. Equity (Keadilan), kepuasan kerja seseorang dapat terpenuhi apabila pekerja merasa diperlakukan dengan adil.
5. Dispositional/ Genetic Components (Komponen genetik), kepuasan kerja antara satu orang dengan orang lainnya dapat berbeda tergantung dengan kepribadian masing-masing.

\section{Teori Stress Kerja}

Menurut Umar (2008) stress didefinisikan sebagai suatu situasi ataupun kondisi dimana terjadi ketegangan pada diri seseorang yang dapat mempengaruhi emosi, cara berpikir dan kondisinya. Menurut Handoko (2001) stress terbagi atas 2 kategori, yaitu:

1. On-The-Job, merupakan kondisi kerja yang seringkali menimbulkan stress terhadap karyawan.

2. Off-The-Job, merupakan masalah-masalah yang terjadi di luar perusaahaan yang dapat menyebabkan stress pada karyawan.

Luthans (2005) menjelaskan terdapat 4 penyebab terjadinya stress, yakni;

1. Stressor Ekstraorganisasional

2. Stressor Organisasional

3. Stressor Kelompok

4. Stressor individu

\section{Teori Turnover Intention}

Menurut Tett dan Meyer (dalam Egan, dkk, 2004) turnover intention merupakan keinginan yang terencana atau rencana seseorang untuk meninggalkan perusahaan atau organisasi yang didudukinya. Syafrizal (2011) menyebutkan faktor-faktor yang mempengaruhi turnover intention karyawan antara lain;

1. Usia

2. Lama Kerja

3. Tingkat Pendidikan dan Intelegensi

4. Keikatan terhadap Perusahaan

5. Kepuasan Kerja

Hubungan Time Demands of Work dengan Turnover Intention Karyawan

Penelitian yang dilakukan oleh Wickramasinghe (2010) menunjukkan bahwa time demands of work berpengaruh positif terhadap turnover intention karyawan. Hal ini menunjukkan bahwa semakin tinggi tuntutan waktu kerja yang dibebankan kepada karyawan atau semakin banyak waktu yang dihabiskan untuk menyelesaikan pekerjaannya maka semakin besar keinginan karyawan untuk keluar dari pekerjaannya. Dari uraian tersebut diajukan hipotesis sebagai berikut:

H1: Time demands of work berpengaruh positif terhadap turnover intention karyawan. 


\section{Hubungan Time Demands of Work dengan Kepuasan Kerja \\ Penelitian yang dilakukan oleh} Wickramasinghe (2010) menunjukkan bahwa time demands of work berpengaruh negatif terhadap kepuasan kerja. Ini menunjukkan bahwa semakin tinggi time demands of work maka semakin rendah kepuasan kerja karyawan, dengan kata lain semakin suatu pekerjaan menyita banyak waktu yang dimiliki karyawan maka akan semakin rendah tingkat kepuasan kerja karyawan atau karyawan akan merasa tidak puas. Dari uraian di atas maka diajukan penelitian sebagai berikut:

H2: Time demands of work berpengaruh negatif terhadap kepuasan kerja.

Hubungan Kepuasan Kerja dengan Turnover Intenton

Penelitian mengenai hubungan antara kepuasan kerja dengan turnover intention karyawan dilakukan oleh Wickramasinghe (2010), dalam penelitian ini ditemukan bahwa kepuasan kerja karyawan berpengaruh negatif terhadap turnover intention karyawan. Hal ini dapat diartikan bahwa kepuasan kerja akan meminimalkan keinginan karyawan untuk keluar dari pekerjaannya, sebaliknya karyawan yang tidak merasa puas terhadap pekerjaannya cenderung menginginkan untuk keluar dan mencari pekerjaan lain. . Dari uraian di atas maka diajukan hipotesis sebagai berikut:

H3: Kepuasan kerja berpengaruh negatif terhadap turnover intention karyawan.

Hubungan Time Demands of Work, Kepuasan Kerja, dan Turnover Intention Penelitian terdahulu mengenai hubungan antara time demands of work, kepuasan kerja, dan turnover intention dilakukan oleh Wickramasinghe (2010). Dalam penelitian ini ditemukan hasil bahwa kepuasan kerja karyawan berhasil memediasi hubungan antara time demands of work dengan turnover intention karyawan. Dengan kata lain time demands of work memiliki pengaruh tidak langsung terhadap turnover intention karyawan yang dimediasi oleh kepuasan kerja. Dari uraian di atas maka diajukan hipotesis sebagai berikut:

H4: Kepuasan kerja akan memediasi hubungan antara time demands of work dengan turnover intention karyawan.

\section{Hubungan Time Demands of Work dengan Stress Kerja}

Penelitian terdahulu yang dilakukan oleh Tetsunojo Uehata (1991) menghasilkan suatu kesimpulan bahwa jam kerja yang panjang melebihi jam kerja normal akan memicu stress pada karyawan. Konsep mengenai hubungan antara time demands of work terhadap stress kerja diperkuat oleh Fred Luthans (2005), dalam konsep tersebut menyebutkan bahwa pekerja yang bekerja overtime berpengaruh signifikan terhadap tingkat stress yang tinggi. Karyawan yang menghabiskan sebagian besar waktu yang dimilikinya untuk menyelesaikan pekerjaan akan sangat mungkin merasa bosan sehingga dapat menimbulkan stress yang ditandai dengan kesehatan yang menurun dan kebiasaan yang kurang baik. Berdasarkan uraian di atas maka diajukan penelitian sebagai berikut:

H5: Time demands of work berpengaruh positif terhadap stress kerja karyawan.

Hubungan Stress Kerja dengan Turnover Intention

Penelitian terdahulu yang dilakukan oleh Sischa Nardiana (2014) memberikan suatu hasil bahwa stress kerja berpengaruh positif terhadap turnover intention karyawan. Hal ini memberikan kesimpulan bahwa semakin tinggi tingkat stress yang dialami seseorang maka semakin tinggi juga keinginan karyawan untuk mengundurkan diri atau keluar dari pekerjannya. Hani Handoko (2001) menjelaskan bahwa akibat paling ekstrim dari stress kerja yang tinggi pada karyawan ialah keluar (turnover) atau melarikan diri dari pekerjaan, dan mungkin diberhentikan oleh perusahaan. Berdasarkan uraian di atas maka diajukan hipotesis penelitian sebagai berikut:

H6: Stress kerja berpengaruh positif terhadap turnover intention karyawan.

Hubungan Time Demands of Work, Stress Kerja, dan Turnover Intention

Wickramasinghe (2010) menyebutkan bahwa time demands of work berpengaruh positif terhadap turnover intention, hal ini berarti semakin besar tuntutan waktu kerja yang dibebankan akan meningkatkan keinginan karyawan tersebut untuk keluar dari perusahaan. Sedangkan Uehata (1991) menyebutkan bahwa tuntutan time demands of work berpengaruh positif terhadap stress 
kerja. Berdasarkan atas uraian di atas maka diajukan hipotesis penelitian sebagai berikut:

H7: Stress kerja akan memediasi hubungan antara time demands of work dengan turnover intention karyawan.

\section{Hubungan Stress Kerja dengan Kepuasan} Kerja

Penelitian yang dilakukan oleh Silalahi (2014) menyebutkan bahwa stress kerja berpengaruh negatif dengan kepuasan kerja. Secara lebih rinci dijelaskan bahwa semakin besar karyawan merasa stress maka kepuasan kerjanya akan semakin menurun. Seseorang yang mengalami stress cenderung menganggap pekerjaannya sebagai beban. Berdasarkan uraian diatas mengenai hubungan stress kerja dengan kepuasan kerja karyawan maka diajukan penelitian sebagai berikut:

H8: Stress kerja berpengaruh negatif terhadap kepuasan kerja karyawan.

Hubungan Stress Kerja, Kepuasan Kerja, dan Turnover Intention

Penelitian terdahulu oleh Apllebaum, dkk (2010) menyebutkan bahwa stress berpengaruh signifikan terhadap kepuasan kerja. Kemudian kepuasan kerja dihubungkan dengan variabel turnover intention menghasilkan bahwa kepuasan kerja berpengaruh signifikan dan positif terhadap turnover intention. Berdasarkan uraian di atas maka diusulkan hipotesis penelitian sebagai berikut

H9: Kepuasan kerja akan memediasi hubungan antara stress kerja dengan turnover intention.

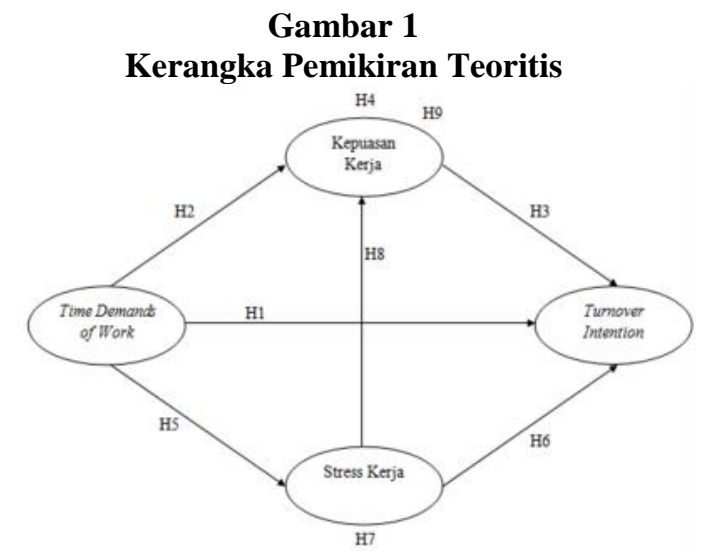

Sumber: Dikembangkan untuk penelitian ini

\section{METODE PENELITIAN}

Variabel yang digunakan dalam penlitian ini terbagi atas tiga variabel, variabel independen yakni time demands of work (TDW), variabel intervening yakni kepuasan kerja (KK) dan stress kerja (SK), dan variabel dependen yakni turnover intention (TI). Responden penelitian merupakan kayawan PT. Bank Tabungan Negara (Persero) Tbk. Cabang Harapan Indah, Bekasi. Populasi penelitian ialah seluruh karyawan berjumlah 108 orang. Sampel diterapkan menggunakan sensus, yakni seluruh populasi sebanyak 108 karyawan, namun terjadi penurunan sampel menjadi 85 karyawan. Sehingga sampel yang diterapkan dalam penelitian ini sebanyak 85 karyawan.

Data yang digunakan dalam penelitian ini berupa hasil wawancara peneliti dengan pihak perusahaan serta hasil dari kuesioner yang disebar kepada responden. Kuesioner berupa persepsi responden berdasarkan pertanyaan yang berasal dari indikator yang ditetapkan. Skala yang digunakan dalam kuesioner menggunakan skala likert (likert scale) yakni skala 1 sampai dengan skala 5.

Time demands of work diukur menggunakan tiga indikator (bekerja dengan jam kerja lebih, pergi bekerja saat akhir pekan, membawa tugas yang belum selesai saat pulang dari kantor). Kepuasan kerja diukur dengan lima indikator (pekerjaan itu sendiri, gaji, supervisi, hubungan dengan teman kerja, kesempatan promosi). Stress kerja dihitung menggunakan lima indikator (fisiologis, kognitif, subyektif, perilaku, keorganisasian). Turnover intention diukur menggunakan tiga indikator (pikiran untuk keluar, keinginan mencari lowongan kerja 


\section{Hasanah and Suharnomo./Jurnal Studi Manajemen \& Organisasi 13 (2016) Desember 110 - 120 http://ejournal.undip.ac.id/index.php/smo}

lain, keinginan meninggalkan organisasi beberapa waktu mendatang).

Alat olah data yang digunakan dalam penelitian ini ialah SmartPLS (Partial Least Squre). Cara kerja PLS terdiri atas dua tahap, yakni Outer Model (model pengukuran) dan Inner Model (model struktural). Outer model terdiri atas uji validitas (Convergent Validity dan Discriminant Validity) dan uji reliabilitas. Inner model terdiri atas uji $R$ Square dan uji hipotesis analisis jalur.

\section{HASIL DAN PEMBAHASAN \\ Outer Model \\ Convergent Validity}

Uji convergent validity model pengukuran dilihat berdasarkan nilai loading factor masing-masing konstruk. Menurut Chin (1998 dalam Ghozali, 2009) pada penelitian tahap awal dari pengembangan skala pengukuran nilai loading factor 0,5 sampai 0,6 dianggap sudah cukup memadai. Berdasarkan hal tersebut maka konstruk yang memiliki nilai dibawah 0,5 dianggap tidak memenuhi convergent validity sehingga konstruk harus didrop dari analisis (Ghozali, 2009). Pada penelitian ini model awal belum memenuhi validitas karena nilai dibawah 0,5 oleh karena itu dilakukan modifikasi sebanyak dua kali sehingga model memenuhi validitas.

\section{Discriminant Validity}

Discriminant validity dapat dilihat pada tabel cross loadings. Jika setiap nilai loading dari setiap konstruk dari sebuah variabel laten memiliki nilai loading yang paling besar dibandingkan dengan nilai loading lain terhadap variabel laten lainnya maka model tersebut dikatakan memiliki discriminant validity yang baik. Berdasarkan tabel dapat dilihat bahwa nilai cross loading tiap-tiap konstuk variabel laten yang dituju memiliki nilai yang lebih besar dibandingkan dengan nilai loading konstruk variabel lainnya. Oleh karena itu dapat disimpulkan bahwa konstruk memiliki discriminant validity yang baik.

Tabel 1

Cross Loading

\begin{tabular}{|c|c|c|c|c|}
\hline & KK & SK & TDW & TI \\
\hline KK1 & $\mathbf{0 . 7 6 9 6 6}$ & -0.32466 & -0.12877 & -0.45914 \\
\hline KK2 & $\mathbf{0 . 5 2 4 8 4}$ & -0.38851 & -0.29258 & -0.26477 \\
\hline KK3 & $\mathbf{0 . 6 4 9 3 8}$ & -0.33247 & -0.05684 & -0.18926 \\
\hline KK4 & $\mathbf{0 . 8 3 9 9 5}$ & -0.30081 & -0.10546 & -0.56326 \\
\hline KK6 & $\mathbf{0 . 7 3 1 5 7}$ & -0.238 & -0.04415 & -0.56166 \\
\hline KK8 & $\mathbf{0 . 5 7 1 1 2}$ & -0.11501 & 0.043198 & -0.24956 \\
\hline SK1 & -0.16774 & $\mathbf{0 . 7 6 4 9}$ & 0.288552 & 0.265591 \\
\hline SK11 & -0.36097 & $\mathbf{0 . 7 7 4 9 6}$ & 0.322905 & 0.339788 \\
\hline SK12 & -0.15367 & $\mathbf{0 . 6 0 5 1 6}$ & 0.212639 & 0.186098 \\
\hline SK13 & -0.47917 & $\mathbf{0 . 7 2 3 2 4}$ & 0.330066 & 0.556388 \\
\hline SK2 & -0.17314 & $\mathbf{0 . 7 7 9 6 5}$ & 0.309094 & 0.316822 \\
\hline SK3 & -0.32684 & $\mathbf{0 . 8 2 7 3 2}$ & 0.268955 & 0.337782 \\
\hline SK4 & -0.20151 & $\mathbf{0 . 8 0 4 1 1}$ & 0.312677 & 0.305594 \\
\hline SK5 & -0.28509 & $\mathbf{0 . 8 4 0 4 9}$ & 0.38601 & 0.319858 \\
\hline SK7 & -0.37822 & $\mathbf{0 . 8 5 5 5 4}$ & 0.423067 & 0.368493 \\
\hline SK8 & -0.24029 & $\mathbf{0 . 5 3 1 7 4}$ & 0.139327 & 0.163728 \\
\hline SK9 & -0.38478 & $\mathbf{0 . 5 5 5 3 9}$ & 0.178403 & 0.285594 \\
\hline IDW1 & -0.14431 & 0.329364 & $\mathbf{0 . 8 2 9 7 9}$ & 0.194353 \\
\hline TDW2 & -0.22267 & 0.372051 & $\mathbf{0 . 7 3 3 4 4}$ & 0.10103 \\
\hline TDW3 & -0.12854 & 0.423866 & 0.90337 & 0.295875 \\
\hline IDW4 & -0.06978 & 0.281334 & $\mathbf{0 . 7 8 5 3 2}$ & 0.171961 \\
\hline TDW5 & -0.01315 & 0.179675 & $\mathbf{0 . 7 6 1 5 6}$ & 0.061857 \\
\hline TDW6 & -0.04604 & 0.218202 & $\mathbf{0 . 7 4 0 0 7}$ & 0.194158 \\
\hline TI1 & -0.57914 & 0.38749 & 0.278173 & $\mathbf{0 . 8 8 5 4 4}$ \\
\hline TI2 & -0.29059 & 0.245575 & 0.124468 & $\mathbf{0 . 7 5 4 0 7}$ \\
\hline T13 & -0.61147 & 0.386276 & 0.223725 & $\mathbf{0 . 8 6 8 5 5}$ \\
\hline TI4 & -0.39306 & 0.254567 & 0.213153 & $\mathbf{0 . 5 6 4 5}$ \\
\hline II5 & -0.47791 & 0.487144 & 0.163082 & $\mathbf{0 . 8 7 4 3 6}$ \\
\hline I16 & -0.47814 & 0.4023 & 0.17693 & $\mathbf{0 . 8 6 7 9 8}$ \\
\hline TI7 & -0.55498 & 0.351637 & 0.151713 & $\mathbf{0 . 8 3 4 3 4}$ \\
\hline II8 & -0.49579 & 0.410478 & 0.151987 & $\mathbf{0 . 8 9 1 6 5}$ \\
\hline II9 & -0.51125 & 0.418695 & 0.238136 & $\mathbf{0 . 9 4 6 5 2}$ \\
\hline
\end{tabular}

Sumber: Pengolahan data dengan PLS, 2016

\section{Uji Reliabilitas}

Uji reliabilitas pada alat analisis PLS dapat dilakukan dengan dua cara, yakni composite reliability dan cronbrachs alpha. Menurut Ghozali (2009) instrumen dikatakan reliabel apabila nilai composite reliability $>0,70$. Selain melihat composite reliability, uji reliabilitas juga dapat dilihat dari nilai cronbach alpha $>0,70$. 
Tabel 2

Composite Reliability

\begin{tabular}{|c|c|}
\hline & Composite Reliability \\
\hline KK & 0.841577 \\
\hline SK & 0.929151 \\
\hline TDW & 0.910798 \\
\hline II & 0.954549 \\
\hline
\end{tabular}

Sumber: Pengolahan data dengan PLS, 2016

Tabel 3

Cronbachs Alpha

\begin{tabular}{|c|c|}
\hline & Cronbachs Alpha \\
\hline KK & 0.776638 \\
\hline SK & 0.915187 \\
\hline TDW & 0.886041 \\
\hline II & 0.944831 \\
\hline
\end{tabular}

Sumber: Pengolahan data dengan PLS, 2016

Dari tabel di atas dapat dilihat bahwa nilai composite reliability dan nilai cronbachs alpha keseluruhan variabel memiliki nilai lebih dari 0,70. Oleh karena itu dapat disimpulkan bahwa keseluruhan variabel penelitian dinyatakan memenuhi reliabilitas.

\section{Inner Model R-Square $\begin{array}{rrrr}\text { Menurut } & \text { Ghozali (2009) } & \text { perubahan } \\ \text { yang terjadi pada nilai } & \text { R-Square }\end{array}$ menunjukkan seberapa besar nilai dari pengaruh variabel laten independen tertentu terhadap variabel laten dependen.}

Tabel 4

R-Square

\begin{tabular}{|c|c|}
\hline & R Square \\
\hline KK & 0.171012 \\
\hline SK & 0.16434 \\
\hline TDW & \\
\hline II & 0.410411 \\
\hline
\end{tabular}

Sumber: Pengolahan data dengan PLS, 2016

Berdasarkan pada tabel dapat disimpulkan bahwa:

1. Varibel KK dipengaruhi oleh variabel TDW dan KK sebesar 17,1012\% (lemah)

2. Variabel SK dipengaruhi oleh variabel TDW sebesar 16,434\% (lemah)

3. Variabel TI dipengaruhi oleh variabel TDW, KK, dan SK sebesar 41,0411\% (moderat).

\section{Pengujian Hipotesis}

Menurut Ghozali (2009) suatu hipotesis dinyatakan signifikan atau memiliki pengaruh apabila besarnya nilai korelasi pada tabel path coefficients yakni nilai ( $\mathrm{t}$ hitung $<\mathrm{t}$ tabel 1,96). 
Tabel 5

Path Coefficients

\begin{tabular}{|c|c|c|c|c|c|}
\hline & $\begin{array}{c}\text { Original } \\
\text { Sample (O) }\end{array}$ & $\begin{array}{c}\text { Sample Mean } \\
\text { (MD }\end{array}$ & $\begin{array}{c}\text { Standard } \\
\text { Deviation } \\
\text { (STDEV) }\end{array}$ & $\begin{array}{c}\text { Standard } \\
\text { Error } \\
\text { (STERR) }\end{array}$ & $\begin{array}{c}\text { T Statistics } \\
\text { (O/STERR) }\end{array}$ \\
\hline KK $\rightarrow$ TI & -0.49576 & -0.50737 & 0.067938 & 0.067938 & 7.297279 \\
\hline SK $\rightarrow$ KK & -0.4218 & -0.43605 & 0.104145 & 0.104145 & 4.050148 \\
\hline SK $\rightarrow$ II & 0.218806 & 0.220253 & 0.095544 & 0.095544 & 2.290117 \\
\hline TDW $\rightarrow$ KK & 0.021551 & 0.018049 & 0.104402 & 0.104402 & 0.206421 \\
\hline TDW $\rightarrow$ SK & 0.405388 & 0.415428 & 0.076163 & 0.076163 & 5.322638 \\
\hline TDW $\rightarrow$ TI & 0.06881 & 0.06461 & 0.0972 & 0.0972 & 0.70792 \\
\hline
\end{tabular}

Sumber: Pengolahan data dengan PLS, 2016

\section{Hubungan Time Demands of Work dengan Turnover Intention Karyawan}

Berdasarkan pengujian hipotesis diketahui bahwa pengaruh time demands of work terhadap turnover intention karyawan sebesar 0.70792. Nilai tersebut menunjukkan bahwa time demands of work tidak mempunyai pengaruh yang signifikan terhadap turnover intention karyawan dikarenakan nilai tersebut kurang dari 1,96. Dengan demikian H1 ditolak. Dengan begitu dapat disimpulkan bahwa semakin tinggi maupun semakin rendah tingkat time demands of work maka tidak berpengaruh terhadap turnover intention karyawan.

Hubungan Time Demands of Work dengan Kepuasan Kerja

Berdasarkan pengujian hipotesis diketahui bahwa pengaruh variabel time demands of work terhadap variabel kepuasan kerja sebesar 0.206421. Nilai tersebut menunjukkan bahwa time demands of work tidak mempunyai pengaruh yang signifikan terhadap kepuasan kerja karyawan dikarenakan nilai tersebut kurang dari 1,96. Dengan demikian $\mathrm{H} 2$ ditolak. Oleh karena itu dapat disimpulkan bahwa semakin tinggi ataupun semakin rendah tingkat time demands of work tidak berpengaruh terhadap semakin tinggi atau semakin rendahnya kepuasan kerja karyawan.

\section{Hubungan Kepuasan Kerja dengan Turnover Intenton}

Berdasarkan pengujian hipotesis diketahui bahwa pengaruh variabel kepuasan kerja terhadap variabel turnover intention sebesar 7.297279 dan memiliki hubungan yang negatif. Nilai tersebut menunjukkan bahwa kepuasan kerja memiliki pengaruh negatif dan signifikan terhadap turnover intention. Hal tersebut menunjukkan bahwa semakin tinggi tingkat kepuasan kerja karyawan maka semakin rendah keinginan karyawan untuk keluar dari perusahaan tempat mereka bekerja. Dengan demikian H3 diterima. Hal ini sejalan dengan penelitian yang dilakukan oleh Wickramasinghe (2010) yang menyatakan bahwa kepuasan kerja memiliki pengaruh negatif terhadap turnover intention karyawan.

Hubungan Time Demands of Work, Kepuasan Kerja, dan Turnover Intention

Berdasarkan pengujian hipotesis diketahui bahwa variabel time demands of work tidak mempunyai pengaruh yang signifikan terhadap variabel kepuasan kerja karyawan. Pada tabel tersebut juga menunjukkan bahwa variabel kepuasan kerja berpengaruh negatif dan signifikan terhadap variabel turnover intention. Dengan begitu maka kepuasan kerja gagal menjadi variabel mediasi antara time demands of work dengan turnover intention. Dengan demikian $\mathrm{H} 4$ ditolak. Hal ini memiliki arti bahwa tinggi rendahnya tingkat kepuasan kerja karyawan tidak mempengaruhi hubungan antara time demands of work dengan turnover intention karyawan.

\section{Hubungan Time Demands of Work dengan Stress Kerja}

Berdasarkan pengujian hipotesis diketahui bahwa pengaruh variabel time demands of work terhadap variabel stress kerja sebesar 5.322638 dan memiliki hubungan yang positif. Nilai tersebut menunjukkan bahwa variabel time demands of work berpengaruh positif dan signifikan terhadap stress kerja karyawan. Hal ini menunjukkan bahwa semakin tinggi time demands of work maka semakin tinggi pula tingkat stress kerja karyawan. Dengan demikian H5 diterima. Hal ini sejalan dengan penelitian yang dilakukan oleh Tetsunojo Uehata (1991) yang menyatakan bahwa jam kerja yang panjang berpengaruh positif terhadap stress kerja karyawan.

\section{Hubungan Stress Kerja dengan Turnover Intention}

Berdasarkan pengujian hipotesis diketahui bahwa pengaruh variabel stress 
kerja terhadap variabel turnover intention sebesar 2.290117 dan memiliki hubungan yang positif. Nilai tersebut menunjukkan bahwa variabel stress kerja berpengaruh positif dan signifikan terhadap turnover intention karyawan. Hal ini menunjukkan bahwa semakin tinggi tingkat stress kerja yang dialami karyawan maka semakin tinggi pula keinginan karyawan untuk keluar dari perusahaan tempat mereka bekerja. Dengan demikian H6 diterima. Hal ini sejalan dengan penelitian yang dilakukan oleh Sischa Nardiana (2014) yang menyatakan bahwa stress kerja saling berhubungan positif dengan turnover intention karyawan.

Hubungan Time Demands of Work, Stress Kerja, dan Turnover Intention

Berdasarkan pengujian hipotesis diketahui bahwa variabel time demands of work mempunyai pengaruh yang positif dan signifikan terhadap variabel stress kerja karyawan. Pada tabel tersebut juga menunjukkan bahwa variabel stress kerja berpengaruh positif dan signifikan terhadap variabel turnover intention. Dengan begitu maka stress kerja berhasil memediasi hubungan antara variabel time demands of work dengan turnover intention karyawan. Dengan demikian H7 diterima. Hal tersebut menunjukkan bahwa semakin tinggi atau semakin rendahnya tingkat stress kerja yang dialami oleh karyawan maka dapat mempengaruhi hubungan tuntutan waktu kerja yang dibebankan karyawan terhadap keinginan karyawan untuk keluar dari perusahaan tempat mereka bekerja.

Hubungan Stress Kerja dengan Kepuasan Kerja

Berdasarkan pengujian hipotesis diketahui bahwa pengaruh variabel stress kerja terhadap variabel kepuasan kerja sebesar 4.050148 dan memiliki hubungan yang negatif. Nilai tersebut menunjukkan bahwa variabel stress kerja berpengaruh negatif dan signifikan terhadap kepuasan kerja karyawan. Dengan demikian H8 diterima. Oleh karena itu semakin tinggi tingkat stress kerja yang dialami oleh karyawan maka semakin rendah kepuasan karyawan terhadap pekerjaannya. Hal ini sejalan dengan penelitian yang dilakukan oleh Yosevine Gilberth Silalahi (2014) yang menyatakan bahwa stress kerja berpengaruh negatif terhadap kepuasan kerja karyawan.

Hubungan Stress Kerja, Kepuasan Kerja, dan Turnover Intention
Berdasarkan pengujian hipotesis diketahui bahwa variabel stress kerja mempunyai pengaruh yang negatif dan signifikan terhadap variabel kepuasan kerja karyawan. Pada tabel tersebut juga menunjukkan bahwa variabel kepuasan kerja berpengaruh negatif dan signifikan terhadap variabel turnover intention. Dengan begitu maka kepuasan kerja berhasil memediasi hubungan antara variabel stress kerja dengan turnover intention karyawan. Dengan demikian H9 diterima. Disimpulkan bahwa semakin tinggi atau semakin rendahnya tingkat kepuasan kerja karyawan dapat mempengaruhi hubungan antara stress kerja karyawan dengan keinginan karyawan untuk keluar dari perusahaan tempat mereka bekerja. Hal ini sejalan dengan penelitian yang dilakukan oleh Applebaum, dkk (2010) yang menyatakan bahwa kepuasan kerja memediasi hubungan antara variabel stress kerja dengan turnover intention.

\section{KESIMPULAN}

1. Variabel time demands of work tidak memiliki pengaruh langsung terhadap turnover intention.

2. Variabel time demands of work berpengaruh secara tidak langsung terhadap turnover intention karyawan apabila dimediasi oleh stress kerja karyawan.

3. Variabel kepuasan kerja karyawan gagal menjadi variabel yang memediasi hubungan antara time demands of work dengan turnover intention karyawan.

4. Stress kerja karyawan berpengaruh tidak langsung terhadap turnover intention karyawan apabila dimediasi oleh kepuasan kerja karyawan.

\section{IMPLIKASI MANAJERIAL}

Penelitian ini didapatkan hasil bahwa time demands of work cukup dirasakan oleh karyawan PT. Bank Tabungan Negara (Persero) Tbk. Cabang Harapan Indah, Bekasi. Hal ini mengindikasikan bahwa karyawan seringkali merasakan jam kerja perusahaan cukup berlebih. Sehingga perusahaan disarankan untuk dapat mengevaluasi kembali serta menyusun kembali mengenai jam kerja yang berlaku serta memanage pekerjaan-pekerjaan yang menuntut karyawan bekerja dengan waktu yang cukup berlebih. Perusahaan juga dapat menambah jumlah tenaga kerja sehingga 


\section{Hasanah and Suharnomo./Jurnal Studi Manajemen \& Organisasi 13 (2016) Desember 110 - 120 http://ejournal.undip.ac.id/index.php/smo}

beban pekerjaan yang berlebih dapat dibagi kepada karyawan lain sehingga waktu yang digunakan dalam bekerja juga dapat berkurang.

Persepsi karyawan terhadap variabel time demands of work terbukti dapat memiliki pengaruh langsung terhadap stress kerja karyawan. Selain itu, time demands of work juga terbukti memiliki pengaruh tidak langsung terhadap keinginan karyawan untuk mengundurkan diri dari perusahaan yang dimediasi oleh stress kerja. Oleh sebab itu penting bagi perusahaan untuk menyusun kembali mengenai pembagian beban kerja agar dapat meminimalisir tingkat stress yang dialami karyawan yang juga dapat berdampak tidak langsung terhadap keinginan karyawan untuk keluar dari pekerjaan.

Pada variabel kepuasan kerja didapatkan bahwa kepuasan kerja karyawan PT. Bank Tabungan Negara (Persero) Tbk. Cabang Harapan Indah, Bekasi sudah tinggi. Hal ini mengindikasikan keadaan yang baik bagi karyawan maupun perusahaan. Namun perlu diperhatikan pada beberapa poin pertanyaa kuesioner tentang kepuasan karyawan terhadap gaji menunjukkan tingkat kepuasan sedang. Dari fenomena tersebut dapat disarankan bagi perusahaan untuk mengevaluasi sistem kompensasi perusahaan agar kepuasan karyawan semakin meningkat.

Selain itu, persepsi karyawan terhadap stress kerja menunjukkan nilai sedang/ cukup. Hal ini mengindikasikan bahwa karyawan sewaktu-waktu dapat merasa stress yang diakibatkan dari pekerjaan mereka. Pada penelitian ini dibuktikan bahwa stress yang dialami karyawan dapat mempengaruhi semakin tingginya keinginan karyawan untuk keluar dari perusahaan. Selain itu, stress juga terbukti dapat menyebabkan kepuasan kerja karyawan semakin menurun. Sehingga perusahaan disarankan untuk dapat meninjau kembali mengenai pembagian tugas kepada karyawan. Selain itu, perusahaan juga dapat meninjau kembali mengenai deskripsi pekerjaan dan spesifikasi pekerjaan serta dapat memberikan arahan yang lebih jelas dan terstruktur mengenai pekerjaan-pekerjaan yang harus dikerjakan agar dapat mengurangi tingkat stress yang dialami karyawan.

Selain itu persepsi karyawan mengenai variabel turnover intention menunjukkan tingkat sedang atau cukup. Temuan tersebut mengindikasikan bahwa karyawan seringkali sewaktu-waktu berpikir untuk mengundurkan diri dari perusahaan untuk mencari pekerjaan lain. Keinginan untuk mengundurkan diri dari perusahaan yang dirasakan oleh karyawan perlu mendapatkan perhatian karena apabila dibiarkan akan membawa dampak yang kurang baik bagi perusahaan dan dapat mengganggu kegiatan perusahaan. Dari temuan tersebut didapatkan bahwa keinginan karyawan untuk keluar dari perusahaan disebabkan oleh tingkat stress karyawan, oleh sebab itu kembali lagi bahwa perusahaan harus sedapat mungkin mengurangi stress kerja yang dialami karyawan untuk meminimalisir turnover intention.

\section{DAFTAR PUSTAKA}

Applebaum, Diane, Susan Fowler, Mamcy Fiedler, Omowunmi Osinubi, Mak Robson. 2010. The Impact of Environmental Factors on Nursing Stress, Job Satisfaction, and Turnover Intention. "Journal of Nursing Administration", Vol. 40 No.7-8, pp. 323-328.

Egan, Toby Marshall., et al. 2004. The Effects of Organizational Learning Culture and Job Satisfaction on Motivation to Transfer Learning and Turnover Intention. "Journal of Human Resource Development Quarterly”, Vol. 15 No.3, pp. 279-301.

Ghozali, Prof. Dr. Imam. 2006. Partial Least Square. Semarang: Badan Penerbit Universitas Diponegoro.

Handoko, Hani. 2001. Manajemen Personalia dan Sumberdaya Manusia. Yogyakarta: BPFEYogyakarta.

Huning, Tobias M dan Neal F.Thomson. 2010. The Impact Of Performance Attributions And Job Satisfaction On Turnover Intentions. "Journal of Organizational Culture, Communications and Conflict”, Vol. 15 No. 1, pp. 121.

Kanwar, Y.P.S., A. K. Singh, dan Anitabh Deo Kodwani. 2012 . A Study of Job Satisfaction, Organizational Commitment and Turnover Intent among the IT and ITES Sector Employees. "Journal of Business Perspective", Vol. 16 No. 1 pp. 27-35.

Kreitner, Robert dan Angelo Kinicki. 2001. Organizational Behavior. New York: McGraw-Hill Companies. Inc. 
Kuncoro, Mudrajad. 2004. Metode Kuantitatif. Yogyakarta: Unit Penerbit dan Percetakan AMP YKPN.

Liu, Y, dan H Tanaka. 2002. Overtime work, insufficient sleep, and risk of non-fatal acute myocardial infarction in Japanese men. "Journal of Occupational and Environmental Medicine", Vol. 59 No. 7, pp. 447-451.

Luthans, Fred. 2005. Organizational Behavior. New York: Mc GRAW - HILL.

Nardiana, Sischa. 2014. "Analisis Pengaruh Work Family Conflict dan Ambiguitas Peran terhadap Intention To Quit: Stress Kerja Sebagai Variabel Intervening”. Skripsi. Semarang: Fakultas Ekonomika dan Bisnis Universitas Diponegoro.

Robbins, Stephen dan Timothy A. Judge. 2008. Organizational Behavior. USA: Pearson International Edition, Prentice-Hall.

Silalahi, Yosevine Girlbert. 2014. "Pengaruh Profesionalisme dan Stress Kerja terhadap Kepuasan Kerja Karyawan". Skripsi. Semarang: Fakultas Ekonomika dan Bisnis Universitas Diponegoro.

Sveinsdottir, Herdis, Pall Biering, dan Alfons Ramel. 2005. Occupational stress, job satisfaction, and working environment among Icelandic nurses: A cross-sectional questionnaire survey. "International Journal of Nursing Studies", Vol. 43 No. 7, pp.875-889.

Syafrizal, Gama Dwi. 2011."Analisis Pengaruh Kepuasan Kerja terhadap Turnover Intention Serta Dampaknya terhadap Kinerja Karyawan”. Skripsi. Semarang: Fakultas Ekonomika dan Bisnis Universitas Diponegoro.

Uehata, Tetsunojo. 1991. Long Working Hours and Occupational Stres-Related Cardiovascular Attacks Among Middle-Aged Workers in Japan. "Journal of Human Ergol”, Vol. 20 No. 2, pp. 147-153.

Umar, Husein. 2008. Desain Penelitian MSDM dan Perilaku Karyawan. Jakarta: Rajawali Pers.

Wickramasinghe, Vathsala. 2010. Impact of time demands of work on job satisfaction and turnover intention. "Strategic Outsourcing: An International Journal", Vol. 3 No. 3, pp. 246-255. 